\title{
On Risk Control Strategy of Cross-border Mergers and Acquisitions of Chinese Enterprises
}

\author{
Jiaxiang Ye ${ }^{1, a}$, Sai Zou ${ }^{2, b}$ \\ ${ }^{1}$ Durham business school (MSc Management (finance)), Durham University, Durham, United Kingdom, DH1, 3DE. \\ ${ }^{2}$ Adam business school (MSc management), University of Glasgow, Glasgow, Scotland, G12 8QQ \\ a491923583@qq.com \\ b2273185010@qq.com
}

\begin{abstract}
Since China joined the World Trade Organization and with the rapid development of global economy integration, Chinese enterprises have entered new era of development under the heat of cross-border mergers and acquisitions and become SSSS technical and financial support for national development. However, high risks exist in their commercial development regarding how to balance the market and deal with cultural contradictions between countries, and how to eliminate various risks and resolve conflicts. From the whole perspective, cross-border mergers and acquisitions involve complicated and systematic engineering. To realize cross-border mergers and acquisitions, Chinese enterprises have adopted strategies mainly based on expansion of scale and regions, but they are still in the preliminary stage of risk control with immature strategies and experience. Based on analysis of the status and features of cross-border mergers and acquisitions of Chinese enterprises, this paper discussed relevant risks during the process and put forward some strategies of risk control, providing reference for Chinese enterprises to realize cross-border mergers and acquisitions.
\end{abstract}

Keywords: Chinese Enterprises, Cross-border Mergers and Acquisitions, Risk Control, Strategy.

\section{STATUS AND FEATURES OF CROSS-BORDER MERGERS AND ACQUISITIONS OF CHINESE ENTERPRISES}

Currently, China has become the world's second largest economy with the increasing comprehensive strength of its enterprises. On the one hand, it's a significant strategic plan for the enterprises to carry out cross-border mergers and acquisitions during their development, which not only help them to open the global market, increase the brand competitiveness and realize value chain upgrading, but also help to optimize resource allocation worldwide. On the other hand, with changing international environment, Chinese enterprises need to define the challenges and risks of cross-border mergers and acquisitions and control the risks. Only with robust risk control strategy taken can they realize target benefits [1].

Cross-border mergers and acquisitions include the processes of merger and acquisition. With increasing capital strength, Chinese enterprises paid for the mergers and acquisitions of enterprises in some fields in other countries, managed and operated them to realize the strategic goal of international development [2]. Therefore, cross-border mergers and acquisitions involve no less than two countries facing different market environments and legal systems as well as more development risks[3].

\subsection{Increasing Number and Expanding Scale of Cross-border Mergers and Acquisitions}

In recent years, Chinese enterprises have taken part in an increasing number of cross-border mergers and acquisitions, which attracted large attention from the public. The transaction value and scale have been also expanding. According to the data revealed by Pricewaterhouse Coopers, the cross-border business transaction volume was around 50 billion dollars in 2010, while in 2016 the number exceeded 200 billion. And according to the latest data [4], China has become the world's largest cross-border acquirer with 678 billion dollars of mergers and acquisitions of mainland 
enterprises in 2018, and the number keeps growing steadily. Cross-border mergers and acquisitions have become an inevitable trend in economy growth [5]. Chinese enterprises have been keen on expanding European market, and the volume of mergers and acquisitions will largely increase in the future. In the meantime, the number of cross-border mergers and acquisitions of Chinese private enterprises has been larger than that of state-owned enterprises for consecutive three years. According to McKinsey, Chinese enterprises are still at the preliminary stage of cross-border investment, thus their transaction volume will be several times larger in the following ten years [6].

\subsection{Diverse Investment Subjects Dominant in the Tertiary Industry}

Chinese enterprises have gradually accumulated experience in the process of strategic development of cross-border mergers and acquisitions. They have already got rid of the traditional idea of blind diversification. Currently, horizontal mergers and acquisitions has become the main strategic plan and method of cross-border mergers and acquisitions. Although conglomerate mergers and acquisitions takes up a certain proportion of the whole, Chinese enterprises are not mature in this method of vertical acquisition which mainly adopted in the industrial industry with great limitation and risks [7]. In the market of mergers and acquisitions, most enterprises are large-scale state-owned enterprises that play a leading role in their industries. According to the big data, the mergers and acquisitions mainly involved secondary and tertiary industries, while in the first industry they took up a small proportion. Up to 2018, data showed that the proportion of electric energy, industry and material in the market of mergers and acquisitions was $41 \%, 16 \%$ and $8 \%$. In terms of industries, Chinese enterprises gradually changed from steel and petrol energy industries to technical service industries such as biotech and automobile [8].

\subsection{Enterprises with Poor Operation as the Target of Cross-border Mergers and Acquisitions}

According to big data analysis, most overseas enterprises emerged and acquired by Chinese enterprises were under poor operation. The negotiation and transaction were conducted when the target enterprises encountered operational issues or bankruptcy, which increased the probability of successful acquisition. For instance, on April 10, 2018, Qingdao Doublestar Co., Ltd. performed official acquisition of South Korea Kumho Tire Co., Ltd. Before the acquisition, the international ranking of Kumho Tire was 14, while Doublestar ranked at 34 .
Normally, the acquisition was impossible. However, due to poor operation of Kumho Tire, many quality issues had been exposed and the enterprise had even been official criticized in CCTV " 315 Gala", losing the trust of the public, as well as its market share and revenue in Chinese market. Finally, in 2016, the enterprise was trapped in debt crisis and delisted by creditor banks. Under this occasion, Chinese enterprise Doublestar Group seized the opportunity for cross-border merger and acquisition and became the largest tire manufacturer in Chinese market, ranking among TOP 10 in the world. Such cases often occur in mergers and acquisitions of Chinese enterprises.

\section{RISKS OF CROSS-BORDER MERGERS AND ACQUISITIONS OF CHINESE ENTERPRISES}

\subsection{Political and Legal Risks}

Cross-border mergers and acquisitions involve market policies in different countries and face certain political and legal risks. Government policy restrictions may have a negative influence on mergers and acquisitions. Political risks include political reforms, emergencies, systems and regulations. For instance, the changes of the leaders and securities will result in the risks of freezing, confiscation and requisition of capital. Since the cash flow between countries has a great influence on political development, the cross-border mergers and acquisitions are under strict control and approval mechanism according to different political environment. The measures were taken for the sake of national economic safety, which will pose certain risks for some enterprises. For instance, during the acquisition of overseas enterprises, once it's objected by the political circles, the business acquisition will end in failure under political pressure. As for legal risks, countries have made relevant laws and regulations to standardize cross-border mergers and acquisitions, resulting in different legal restrictions. For instance, to keep the market fair and competitive, western countries have promulgated Anti-Monopoly Law to restrict cross-border mergers and acquisitions to some extent. Chinese enterprises sometimes are passive and under great restrictions during mergers and acquisitions due to lack of understanding of national regulations of target enterprises, and after mergers and acquisitions, they will face legal risks of environment protection, labor organization and intellectual property.

\subsection{Risk Evaluation}

Currently, while analyzing the cases of mergers and acquisitions of Chinese enterprises, we found certain evaluation risks existed in some Chinese enterprises, that is, they lacked sufficient understanding of the enterprises to be merged and acquired, and 
consideration in strategic and financial rationality, mainly because of great distance between the enterprises. With the target enterprise in another country, it was hard for the acquirer to fully understand the operation status of the target enterprise, resulting in information differences. Cross-border trade also made it difficult to obtain accurate information and changes of the market, leading to unreliable acquisition plan. After cross-border mergers and acquisitions, certain risks arose in the Chinese enterprise because the potential sales and profits of the target enterprise were difficult to evaluate accurately. Therefore, before cross-border mergers and acquisitions, the enterprises needed to fully understand the economic industry structure of global market and carry out background investigation of the market. Based on current situation, the costs of acquisition were high, and most enterprises were under poor operation or with bad business performance, leading to integration risks of human resources and time after acquisition. All these potential risks should be properly evaluated at the preliminary stage of acquisition.

\subsection{Financing Risks}

Chinese enterprises must have abundant capital to achieve cross-border mergers and acquisitions. However, most Chinese enterprises can't afford to complete the acquisition project with their own capital, so they need external financing to meet the requirements of the acquisition. Before mergers and acquisitions, the common ways of financing for Chinese enterprises are through bank loans and stock issuance. Applying for bank loans won't change the ownership structure of enterprises, but it requires the enterprise to pay for the interests to the bank regularly, which increases the operation pressure for the enterprises, leading to financial crisis easily. Issuing stock has its advantage of relieving financial pressure, but it will change the original ownership structure of the enterprises by reducing original equity interests and proportion of self-holding shares. Considering the immature development of capital market and some financial institutions in China, and with certain restrictions of financing channels and financial risks of interest rate and exchange rate, the enterprises should adopt flexible financing methods according to their own development status. At present, securities trading is the main financing method.

\subsection{Integration Risks after Mergers and Acquisitions}

After mergers and acquisitions, the main tasks of the enterprises are business integration and management of the acquirer and the acquired. However, Chinese enterprises are facing great integration risks since they are at the preliminary stage to implement cross-border mergers and acquisitions with immature experience. On the one hand, the enterprises are in shortage of professional experts in acquisition and integration. On the other hand, different national conditions lead to great differences in enterprise culture and management mode, which makes the management systems incompatible, resulting in the loss of talents. The cultural differences will lead to cultural contradictions during integration and operation. Finance is the focus during mergers and acquisitions. Without effective sales and marketing strategies, many integration issues will certainly arise.

\section{RISK CONTROL STRATEGIES FOR CROSS-BORDER M\&A OF CHINESE COMPANIES}

\subsection{Establishing Risk Control Awareness}

The first thing that Chinese companies need to do in cross-border M\&A is to establish an awareness of risk management, which means that the person in charge of the company needs to have the awareness to identify, prevent and control potential risks. Therefore, in the early stages of cross-border M\&A, business leaders and managers need to strengthen risk awareness, develop reliable risk prevention and control plans, and formulate relevant emergency control measures for risks that may arise. Firstly, enterprises need to have a detailed understanding of their own business situation, so that they can fit the relevant business characteristics when choosing the target enterprises for cross-border M\&A, which can help reduce the integration risk. In addition, it is necessary to learn more about the prospects of the industry, which can help improve the overall competitiveness of the enterprise and is a great help to the future development of the enterprise. Finally, the timing of the merger and acquisition should also be controlled.

\subsection{Formulating a Scientific and Reasonable M\&A Strategy}

Before mergers and acquisitions, it is necessary to comprehensively analyze the resources and development prospects of the merged company, conduct quality surveys on the external environment that the company faces, and formulate future development financial strategies based on the actual operating conditions of both parties to ensure the scientific and rationality of the merger strategy. Moreover, it is also important to seize the advantage and determine the best time for mergers and acquisitions. In addition, the process of developing strategic plans should be considered from the perspective of globalization. Comprehensive analysis of the international current situation and finding ways to adapt to both sides of the M\&A, so that companies 
can use international operations to achieve stepwise economic growth and promote long-term sustainable footing in international competition through the huge synergy effects and leapfrogging of both sides brought about by cross-border M\&A. What's more, enterprises should have clear and definite strategic objectives of cross-border M\&A, implement effective measures and clarify the direction of development after M\&A. Only in this way can the risks of M\&A be effectively avoided and the overall strength of the company can be continuously strengthened.

\subsection{Improving the Ability to Analyze $M \& A$ Risks}

Chinese companies are supposed to collect more information about the acquirer, and update relevant data on the economic level, income and expenditure, resource investment and government relations of the acquired companies so that they can analyze the risks and make predictions and evaluations. In addition, we must always pay attention to the information service platforms of the Ministry of Commerce of the People's Republic of China and the China Council for the Promotion of International Trade to grasp the international timely risk dynamics. Furthermore, Moody's, Standard \& Poor's, Euromoney and other authoritative institutions will rank the country-specific political risks year by year, from which we can grasp the changes in the potential political risks of cross-border M\&A, thereby better evaluating the risk level. The two countries also need to do a good job of handling public relations between them, including understanding foreign regulations and laws, gaining support from public opinion, and handling the relationship between Human Resource Management and Unions, thus eliminating the M\&A resistance of other governments and people. In terms of regulation, Chinese companies' cross-border mergers and acquisitions should be particularly wary of investing in categories of state-regulated and restricted industries, such as telecommunications, securities, banking, broadcasting, defense, etc., and give full attention to the legal provisions on anti-monopoly [4].

\subsection{Building a Risk Control System to Optimize the Financing Structure}

Companies need to establish a sound risk control system and set up professional risk control departments to quickly identify M\&A risk factors and conduct scientific evaluation of risk factors so as to truly reflect the objective operating conditions of the M\&A company. It is also necessary to train talents with professional skills and comprehensive strength to be the gatekeeper of the enterprise's risk control. As well, it is possible to organize experienced teams to systematically evaluate risks by hiring mature intermediaries to cooperate and assess the risks of the target company. In order to effectively avoid financing risks, companies need to optimize their own financing structure. According to their overall asset structure, they should choose external financing to reduce financial risks. In order to improve cross-border M\&A financing capacity as well as to broaden financing channels, the Chinese government needs to introduce relevant preferential policies, such as encouraging enterprises to develop international financing channels through overseas investment funds, absorbing funds from international circles and expanding overseas financing sources.

\subsection{Speeding up the Construction of the Legal System}

China's cross-border M\&A laws and regulations are not perfect, so the government should absorb the successful experience of foreign advanced cross-border M\&A legislation and continuously improve the laws and regulations related to cross-border $\mathrm{M} \& \mathrm{~A}$ according to the national conditions, and the laws and regulations should be in line with international standards and combined with the national conditions, thereby providing policy support for Chinese enterprises' overseas M\&A activities. The imperfections of my country's laws and regulations are mainly reflected in the lack of a scientific, transparent, and efficient external merger approval system. The system is not perfect and the workflow is not unified, which leads to an incomplete system of M\&A and the work content is not unified. Therefore, the system is not very operable and the judicial enforcement system cannot effectively regulate the market behavior. Since joining the WTO and implementing CEPA, China has faced a more transparent, intense and flexible international market environment. Therefore, it is necessary to combine international law rules and international practices to improve the rules and regulations of foreign mergers and acquisitions, and to promote the construction of my country's legal system [5].

\section{CONCLUSION}

In order to improve risk control capabilities, Chinese companies need to form an international team with both knowledge of international market rules and professional skills, and negotiates with target companies in a scientific and reasonable way, so as to obtain the strategic assets needed for the development of the international market. Through diplomatic channels, we can make local governments give cross-border M\&A companies a relaxed business environment and play the role of human resources, private equity and investment funds. In addition, enterprises in cross-border M\&A should choose reasonable financing methods, develop scientific and 
effective risk diversification, adjustment and control measures to ensure adequate $\mathrm{M} \& \mathrm{~A}$ funds and avoid debt risks, thereby reducing financing risks. First, in order to enhance the stability of capital, we analyze the maturity structure of assets and liabilities to find the timing of cash flow and capital shortage in formal channels, so as to continuously adjust the internal asset organization structure to prevent liquidity risk. Second, innovative financing methods can be used to reduce the risks associated with changes in interest and exchange rates by financing in the country of the acquired company and by conducting currency swaps, futures transactions, interest rate swaps and option transactions in the foreign exchange market.

\section{REFERENCES}

[1] Jia Zhifan, Ma Zhongmin. Research on Risk Control Strategies of Chinese Enterprises' Cross-border Mergers and Acquisitions[J]. China Business Forum, 2019(17): 106-107.

[2] Xiaoming, \& Qiao. (2018). Analysis on the Risk Control and Development Strategy of Futures Company in China.

[3] Zheng, Y., Meng, C., Wang, Z., Li, C. , \& Wu, Y. . (2019). Risk Control Optimization Models of Different Power Market Purchasing Combinations of Power Selling Companies. 2019 IEEE 3rd Conference on Energy Internet and Energy System Integration (EI2). IEEE.

[4] Yao, D., \& Fan, K.. (2018). Optimal risk control and dividend strategies in the presence of two reinsurers: variance premium principle. Journal of industrial and management optimization, 14(3), 1055-1083.

[5] Meizhi, FAN, Wenxian, WENG, School, \& of, et al. (2017). Risk management strategy for agricultural operation subjects in simple scale expansion mode. Asian Agricultural Research, 07(v.9), 45-47.

[6] Junaidi, J. (2020). Working capital strategy and operation risk in the food and beverage companies listed in the indonesia stock exchange.

[7] Gaillardetz, P., \& Hachem, S. . (2019). Risk-control strategies.

[8] Li, S., \& He, Y. . (2020). Optimal time-consistent investment and reinsurance strategy under time delay and risk dependent model. Mathematical Problems in Engineering, 2020. 